\title{
An intelligent fuzzy regression approach for affective product design that captures nonlinearity and fuzziness
}

\author{
K.Y. Chan ${ }^{* b}$, C.K. Kwong ${ }^{a}$, T.S. Dillon ${ }^{b}$ and K.Y. Fung ${ }^{a}$ \\ ${ }^{b}$ Digital Ecosystems and Business Intelligence Institute, \\ Curtin University of Technology, Australia; ${ }^{a}$ Department of Industrial and Systems Engineering, The \\ Hong Kong Polytechnic University, Hung Hom,Hong Kong, People's Republic of China
}

\section{Abstract}

Affective product design aims at incorporating customers' affective needs into design variables of a new product so as to optimize customers' affective satisfaction. Faced with fierce competition in marketplaces, companies try to determine the settings in order to maximize customers' affective satisfaction with products. To achieve this, a set of customer survey data is required in order to develop a model which relates customers' affective responses to the design variables of a new product. Customer survey data is usually fuzzy since human feeling is usually fuzzy, and the relationship between customers' affective responses and design variables is usually nonlinear. However, previous research on modelling the relationship between affective response and design variables has not addressed the development of explicit models involving either nonlinearity or fuzziness. In this paper, an intelligent fuzzy regression approach is proposed to generate models which represent this nonlinear and fuzzy relationship between affective responses and design variables. In order to do this,

\footnotetext{
${ }^{*}$ K.Y. Chan is the corresponding author. His email address is Kit.Chan@curtin.edu.au.
} 
we extend the existing work on fuzzy regression by first utilizing an evolutionary algorithm to construct branches of a tree representing structures of a model where the nonlinearity of the model can be addressed. The fuzzy regression algorithm is then used to determine the fuzzy coefficients of the model. The models thus developed are explicit, and consist of fuzzy, nonlinear terms which relate affective responses to design variables. A case study of affective product design of mobile phones is used to illustrate the proposed method.

Keywords: Fuzzy regression, evolutionary algorithm, affective product design

\section{Nomenclature}

$\tilde{y}$ is the affective response of the product

$x_{k}$ is the $k$-th design variable of the product where $k=1,2, \ldots N$

$\tilde{A}_{i}$ is the i-th fuzzy coefficient of the fuzzy regression model.

$c_{i}$ is the center of $i$-th fuzzy coefficient of the fuzzy regression model.

$\alpha_{i}$ is the spread of $\mathrm{i}$-th fuzzy coefficient of the fuzzy regression model.

$N_{N R}$ is the number of fuzzy coefficient of the fuzzy regression model.

$x_{k}{ }^{\prime}$ is the transformed $k$-th design variable of the fuzzy regression model where

$$
k=1,2, \ldots N_{N R}
$$

$M$ is the number of data sets.

$h$ refers to the degree to which the fuzzy linear model fits the data sets in developing 
the fuzzy model.

$J$ is the total fuzziness of the regression model.

$y(i)$ is the $i$-th data set with respect to the affective response of the product $\mathrm{w}$

$x^{\prime}{ }_{j}(i)$ is the $j$-th transformed variable of the fuzzy polynomial model of the $i$-th data

set

\section{Introduction}

In today's competitive world, optimization of customer satisfaction is essential in product design in almost every company (Cross 2000). To achieve this, the basic functions and operations of the products must perform satisfactorily. Consumers are ever mindful that the products with which we surround and engage ourselves during our daily tasks need to satisfy needs beyond the functional and operational aspects. For example, in mobile phone design, the basic functions and operations of transmission and receiver must work satisfactorily. After these basic functions and operations have been achieved, higher quality levels are often required. The mobile phone should feel comfortable when hand-held by customers. The buttons of a mobile phone should be able to be punched easily, and voices should be clearly heard by both the transmitter and receiver. At a more advanced level, products in these sectors often need to appeal to a user on an affective level in order to be successful. This is now evident in the mobile phone market where the sector has very successfully 
transformed its products from being merely functional items to lifestyle or fashion accessories (Kuang and Jiang 2008).

This forces designers to find new ways to differentiate their products from those of their competitors in affective product design. Consequently, designers are increasingly focusing on affective satisfaction that products can bring about rather than on their functional benefits. Fulfilling affective satisfaction enriches a person's life and can increase one's general experience of well-being (Diener and Lucas 2000, Kouprie and Visser 2009, Mugge et al. 2009). Accordingly, emotional responses to products can be a decisive factor in purchase decisions (Jordan 2000, Desmet 2002, Norman 2004, Artacho et al. 2009, Nurkka et al. 2009). Therefore, it is essential to optimize the affective satisfaction of a new product. To do this, it is essential to develop an explicit model that relates design variables of a new product to its affective satisfaction.

\subsection{Previous methods}

Kansei engineering (Nagamachi 1995) introduced a concept in product design that emphasized a method for translating affective responses such as 'pretty', 'nice', 'spirited' into design variables. It aims to integrate the customers' feelings and demands into the product design elements. More recent research shows that 
relationships between affective responses and design variables were established mainly through artificial intelligence methods or statistical methods.

Artificial neural networks were first proposed for modeling the relationship between affective responses and design variables in automotive design (Nagamachi 1995). Also, a Kansei engineering rule based system was proposed to generate rules which describe associations automatically based on an approach which incorporated neural networks and Principle Component Analysis (PCA) (Tanoue et al 1997). As a result, a better approximation of women's shoes design can be achieved than the ones achieved by the conventional PCA, using less computational time. More recently, $\mathrm{Gu}$ et al. (2006) proposed an evolutionary system based on neural networks to analyze people's aesthetic evaluations which is able to approximate their implicit aesthetic intentions. It allows the framework to infer which designs the users may find desirable. Chen et al. (2006) developed a prototype system for affective design in which the Kohonen self-organizing map neural network was employed to consolidate the relationship between affective responses and design variables from consumers. The aforementioned neural network based approaches are able to model a nonlinear system as a simplified black-box structure, but these models lack transparency. Therefore, these methods are not appreciated very much by engineering users in model development. 
To address the fuzziness of consumers' responses and the non-linearity of the modeling, artificial intelligence based fuzzy techniques have been used. Hsiao et al. (2005) proposed a method that enables an automatic product form or product image evaluation by means of a neural network-based fuzzy reasoning and genetic algorithm, which was applied to establish relationships between design variables and affective variables. Park and Han (2004), and Lau et al. (2006) adopted the fuzzy rulebased approach for building models which relates affective responses to consumer satisfaction. The above fuzzy modeling based approaches consist of fuzzifiers, fuzzy inference engines, fuzzy rules, and defuzzifiers to determine affective responses based on design variables. Explicit information can be found between affective responses and design variables based on the generated fuzzy rules. However, compared with statistical regression methods that can generate relationships between affective responses and design variables in polynomial form, more explicit information that can express the significance of each design variables and interaction between design variables can be found. Design engineers still prefer to use statistical methods because more explicit information can be found than by using the fuzzy modeling based approaches.

The approach of multiple linear regression (Chuang and Ma 2001, Han et al. 1999, Tanoue et al. 1997, Kuang and Jiang 2008) has been used to model relationships 
between design variables and affective responses. This approach is simple to apply but it assumes that the design variables in the regression are linear, and that the effect of an independent design variable is constant throughout the entire range of the affective response. Under this assumption, more and more terms of design variables are included in the model to fit a wide range of affective responses. It increases the number of terms of design variables in the model of the affective response, and the terms of the design variables involved cannot be guaranteed to be significant for the affective response. Thus, the resulting model is more complex and more difficult to interpret when there are many design variables involved (Han and Hong 2003). A decision support system has been proposed to provide guidelines for optimizing affective satisfaction based on principal component analysis and multiple regression (Barnes and Lillford 2009). An explicit modeling method based on a vectors field based approach has been proposed for modeling the relationship between affective satisfaction and design variables (Petiot and Grognet 2006). You et al. (2006) developed affective satisfaction models using quantification I analysis, which was used to identify significant or preferred design variables for the interior parts of a new product. It uses the statistical method, ANOVA, to screen out the insignificant design variables and then it uses the generalized linear model method to model the affective satisfaction in a perceptual space within which the affective satisfaction of a family of 
products can be described. However, affective satisfaction involve fuzziness which the above statistical approaches are unable to address.

In contrast, fuzzy regression has a distinct advantage in model development, which has a high degree of fuzziness, and it uses only small or incomplete data sets in model development (Tanaka et al. 1982, Takagi and Sugeno 1985, Tanaka and Watada 1988). Fuzzy regression has been applied by Shimizu and Jindo (1995) to model the relationship between affective responses and design variables in order to account for fuzziness of human feelings towards car interior design. However, the existing fuzzy regression approaches cannot be used to develop models which contain nonlinear terms. Kim et al. (1996) reported that fuzzy regression may not be superior to the traditional statistical regression in modeling nonlinear systems. In fact, nonlinear human feelings commonly exist. If nonlinear terms were to be integrated into the approach of fuzzy regression, more accurate models could be developed.

Genetic programming is an evolutionary computational method which can be used to generate models in polynomial form with nonlinear terms (Koza 1992, Koza 1994). It uses the evolutionary operations in genetic programming to generate the structure of models, and the least squares algorithm is then used to perform the coefficient estimation in the models. However, the relationship between design variables and affective responses involves fuzziness due to the nature of human 
feelings. Hence, genetic programming together with the least squares algorithm may not yield the best modeling results, since the methods do not consider the fuzziness due to human feelings.

\subsection{Proposed method}

To overcome the deficiencies of the above approaches, in this paper, an intelligent fuzzy regression approach which can generate explicit models in fuzzy polynomial forms is proposed by considering the fuzziness of consumers' responses and the nonlinearity of the model which captures the relationship between affective responses and design variables. The intelligent fuzzy regression also involves methodological extensions through the use of genetic programming to construct the structure of models in fuzzy polynomial form based on a tree representation where both linear and nonlinear terms can be included. Then, fuzzy regression is used to calculate the fuzzy coefficients of the fuzzy polynomials. Since both linearity and nonlinearity are represented in branches of the tree based on the intelligent fuzzy regression, fuzzy regression models with both fuzzy linear and fuzzy nonlinear terms can be generated. It eliminates the deficiencies of the above approaches which ignore nonlinear terms of relations between design variables and affective satisfactions, as well as the fuzzy nature of data. Moreover, they produce black-box models not usually recommended by engineering users. To evaluate the effectiveness of the proposed intelligent fuzzy 
regression for modeling the relationship between affective variables and design variables, we use mobile phone design. Results of the modeling were compared with those based on the existing fuzzy regression methods (Tanaka et al. 1982, Peters 1994) and statistical regression (Seber 2003).

\section{Intelligent fuzzy regression}

The intelligent fuzzy regression approach generates the fuzzy regression model which relates affective responses and design variables. When defining, the approach needs to:

a) specify the form of the fuzzy model

b) determine the fuzzy coefficients which characterise the model

c) define the algorithm

\section{Specification of the form of the fuzzy model}

In the fuzzy regression model, interactions between design variables and nonlinear terms of design variables are represented in a form of a higher order high-dimensional

Kolmogorov-Gabor polynomial (Friedman 1991), which can be written as

$$
\tilde{y}=\widetilde{f}_{N R}(x)=\widetilde{A}_{0}+\sum_{i_{1}=1}^{N} \widetilde{A}_{i_{1}} x_{i_{1}}+\sum_{i_{1}=1}^{N} \sum_{i_{2}=1}^{N} \widetilde{A}_{i_{1} i_{2}} x_{i_{1}} x_{i_{2}}+\ldots \sum_{i_{1}=1}^{N} \ldots \sum_{i_{d}=1}^{N} \widetilde{A}_{i_{1} \ldots i_{d}} \prod_{j=1}^{d} x_{j}
$$

where $\tilde{y}$ is the affective response; $x_{k}$ is the $k$-th design variable with $k=1,2, \ldots N$; and $\widetilde{A}_{0}=\left(\alpha_{0}, c_{0}\right), \widetilde{A}_{1}=\left(\alpha_{1}, c_{1}\right), \widetilde{A}_{2}=\left(\alpha_{2}, c_{2}\right), \ldots$ 


$$
\begin{aligned}
& \widetilde{A}_{N}=\left(\alpha_{N}, c_{N}\right), \widetilde{A}_{11}=\left(\alpha_{11}, c_{11}\right), \widetilde{A}_{12}=\left(\alpha_{12}, c_{12}\right), \ldots \widetilde{A}_{N N}=\left(\alpha_{N N}, c_{N N}\right), \ldots \\
& \widetilde{A}_{N \ldots N}=\left(\alpha_{N \ldots N}, c_{N \ldots N}\right) .
\end{aligned}
$$

Kolmogorov-Gabor polynomials have been used widely to evolve general nonlinear models by evolutionary methods (Nikolaev and Iba 2001), but no fuzzy coefficient has been considered. The purpose of the proposed fuzzy regression model is to overcome the traditional fuzzy regression (Tanaka et al. 1982, Takagi and Sugeno 1985, Tanaka and Watada 1988) which considers only the linear terms; therefore, only the first two terms of the fuzzy regression model (1) are considered and the rest of the terms are all ignored. It is also intended to supplant the evolutionary methods whereby no fuzzy coefficient can be generated and thus no fuzziness can be addressed.

The fuzzy regression model (1) can be rewritten as:

$$
\begin{gathered}
\tilde{y}=\widetilde{A}_{0}^{\prime} x_{0}^{\prime}+\widetilde{A}_{1}^{\prime} x_{1}^{\prime}+\widetilde{A}_{2}^{\prime} x_{2}^{\prime} \ldots \widetilde{A}_{N_{N R}}^{\prime} x_{N_{N R}}^{\prime} \\
\text { or } \tilde{y}=\left(c_{0}^{\prime}, \alpha_{0}^{\prime}\right) x_{0}^{\prime}+\left(c_{1}^{\prime}, \alpha_{1}^{\prime}\right) x_{1}^{\prime}+\left(c_{2}^{\prime}, \alpha_{2}^{\prime}\right) x_{2}^{\prime}+\ldots\left(c_{N_{N R}}^{\prime}, \alpha_{N_{N R}}^{\prime}\right) x_{N_{N R}}
\end{gathered}
$$

where $1+N_{N R}$ is the number of terms of design variables in (1), (2) and (3); $\widetilde{A}_{0}^{\prime}=\widetilde{A}_{0}$, $\widetilde{A}_{1}^{\prime}=\widetilde{A}_{1}, \widetilde{A}_{2}^{\prime}=\widetilde{A}_{2}, \ldots \tilde{A}_{N_{N R}}^{\prime}=\widetilde{A}_{N \ldots N} ; x_{0}^{\prime}=1, x_{1}^{\prime}=x_{1}, x_{2}^{\prime}=x_{2}, \ldots x_{N_{N R}}^{\prime}=x_{1} \cdot x_{2} \cdot \ldots x_{d} ;$ and $\widetilde{A}_{0}^{\prime}=\left(c_{0}, \alpha_{0}\right), \widetilde{A}_{1}^{\prime}=\left(c_{1}^{\prime}, \alpha_{1}^{\prime}\right), \ldots \widetilde{A}_{N_{N R}}^{\prime}=\left(c_{N_{N R}}^{\prime}, \alpha_{N_{N R}}^{\prime}\right) . \widetilde{A}_{i}^{\prime}$ and $x_{i}^{\prime}$ are called the fuzzy coefficient and the transformed design variable respectively, where $i=0,1,2, \ldots N_{N R}$

\section{Determination of fuzzy coefficients}


The vectors of the fuzzy coefficients are defined as:

$$
\begin{aligned}
& \widetilde{A}^{\prime}=\left(\widetilde{A}_{0}^{\prime}, \widetilde{A}_{1}^{\prime}, \ldots \widetilde{A}_{N_{N R}}^{\prime}\right)=\left(\left(c_{0}^{\prime}, \alpha_{0}^{\prime}\right),\left(c_{1}^{\prime}, \alpha_{1}^{\prime}\right), \ldots\left(c_{N_{N R}}^{\prime}, \alpha_{N_{N R}}^{\prime}\right)\right), \\
& c^{\prime}=\left(c_{0}^{\prime}, c_{1}^{\prime}, \ldots c_{N_{N R}}^{\prime}\right),
\end{aligned}
$$

and $\alpha^{\prime}=\left(\alpha_{0}^{\prime}, \alpha_{1}^{\prime}, \ldots \alpha_{N_{N R}}\right)$.

The vector of the transformed design variables is defined as:

$$
x^{\prime}=\left(x_{0}^{\prime}, x_{1}^{\prime}, x_{2}^{\prime}, \ldots x_{N_{N R}}^{\prime}\right)
$$

Using the vectors of the fuzzy coefficient and the vector of transformed design variables, equation (2) can be rewritten as:

$$
\tilde{y}=\widetilde{A}^{\prime} \cdot x^{T}
$$

Since some terms in (1) may be redundant, prudent selection of significant terms or orders is advisable if a more economical and adequate model is desired. In the intelligent fuzzy regression approach, genetic programming is used to generate the fuzzy regression model which consists of significant terms.

\section{Pseudocode of Algorithm}

The flowchart of the intelligent fuzzy regression is shown in Figure 1 and the pseudocode of the intelligent fuzzy regression used is shown below:

\section{Intelligent fuzzy regression algorithm pseudocode}

Step 1: $t \leftarrow 0$

Step 2: Initialize the population $\Omega(t)=\left[\theta_{1}(t), \theta_{2}(t), \ldots \theta_{P O P}(t)\right]$. $/ / \Omega(t)$ is the population of the fuzzy regression at the $t$-th generation. 
$/ / \theta_{i}(t)$ is the $i$-th individual of $\Omega(t)$ which represents the structure of the fuzzy // regression model(1).

//where $\theta_{k}(t)$ is in polynomial form but no fuzzy coefficient is assigned.

Step 3: Assign fuzzy coefficients to all terms in $\theta_{i}(t)$ by Tanaka et al. (1982)'s fuzzy regression algorithm.

Step 4: Evaluate all $\theta_{\mathrm{i}}(t)$ based on the fitness function (14).

while (Terminational condition not fulfilled) do \{

Step 5: Parent Selection $\Omega(t+1) \leftarrow \Omega(t)$

Step 6: Crossover $\Omega(t+1)$

Step 7: Mutation $\Omega(t+1)$

Step 8: $t \leftarrow t+1$

Step 9: Step 3

Step 10: Step 4

\}

In Step 1, the generation number $t$ is set to 0 . In Step 2, genetic programming creates a random initial population $\Omega(t)$ with $P O P$ individuals, where $\theta_{i}(t)$ is the $i$-th individual. Each individual $\theta_{i}(t)$ is in the form of a tree representation, which can be used to represent the structure of the fuzzy regression model as defined in equation (1). In Step 3, the fuzzy coefficients are assigned to each term of the individual $\theta_{i}(t)$ by applying Tanaka's fuzzy regression (Tanaka et al. 1982, Tanaka and Watada's 1988). In Step 4, all individuals are evaluated based on a defined fitness function which aims at evaluating the goodness-of-fit of the fuzzy regression model. In Step 5, the parent selection process uses the goodness-of-fit of each individual to determine 
the selection of potential individuals for performing crossover in Step 6 and mutation in Step 7. In Step 8, the new individuals with the determined fuzzy coefficients are evaluated using the fitness function in order to create a new population $\Omega(t+1)$. In Step 8 , the generation number $t$ is added by one. The process continues until the predefined termination condition is fulfilled. The major aspects of applying the intelligent fuzzy regression to generate the fuzzy regression model are discussed below:

\subsection{Model Representation}

In intelligent fuzzy regression, hierarchical trees, which are composed of functions in the set $F$ and terminals in the set $T$ (Koza 1992), are used to represent the structure shown in equation (1). $F$ consists of two arithmetic operations, + and $*$, which exist in the fuzzy regression model (1). $T=\{\boldsymbol{x}, \tilde{\mathbf{a}}\}$ contains the design variable set $\boldsymbol{x}=\left\{x_{1}, x_{2}\right.$, $\left.\ldots x_{N}\right\}$ of the fuzzy regression model and the fuzzy coefficient set $\tilde{\mathbf{a}}=$ $\left\{\tilde{a}_{0}, \tilde{a}_{1}, \tilde{a}_{2}, \ldots, \tilde{a}_{N_{N S}}\right\}$ of the fuzzy regression model, where $n$ is the number of design variables and $N_{N S}$ is the number of terms of the fuzzy regression model. The structure of the fuzzy regression model is depicted as a labeled tree with ordered branches, which consists of operations (internal nodes of the tree) $F$ from the function set and arguments (terminal nodes of the tree) from the terminal set $T$. For example, the $i$-th 
individual $\theta_{i}(t)$ represents the following structure of the fuzzy regression model:

$$
\theta_{i}(t)=x_{1}^{2}-x_{2}^{2}+x_{1} \cdot x_{2} \cdot x_{4}
$$

The fuzzy regression model with fuzzy coefficients can be represented by:

$$
\tilde{a}_{0}+\tilde{a}_{1} \cdot x_{1}^{2}-\tilde{a}_{2} \cdot x_{2}^{2}+\tilde{a}_{3} \cdot x_{1} x_{2} x_{4}
$$

where $\tilde{a}_{0}, \tilde{a}_{1}, \tilde{a}_{2}$ and $\tilde{a}_{3}$ are the fuzzy coefficients. It can also be rewritten as:

$$
\tilde{a}_{0}+\tilde{a}_{1} \cdot x^{\prime}{ }_{1}-\tilde{a}_{2} \cdot x_{2}^{\prime}+\tilde{a}_{3} \cdot x^{\prime}{ }_{3}
$$

where $x^{\prime}{ }_{1}=x_{1}{ }^{2}, x_{2}^{\prime}=x_{2}{ }^{2}$ and $x^{\prime}{ }_{3}=x_{1} \cdot x_{2} \cdot x_{4}$

For a fuzzy regression model with $N_{N R}$ terms, the fuzzy coefficients, $\tilde{a}_{0}, \tilde{a}_{1}$, ..

$\tilde{a}_{N S}$ can be determined by solving the following linear programming problem:

$$
\text { Minimize } \quad J=\sum_{j=0}^{N_{\text {NR }}}\left(c^{\prime}{ }_{j} \sum_{i=1}^{M} \mid x_{j}^{\prime}(i)\right)
$$

where $\tilde{a}_{j}=\left(a_{j}^{c}, a_{j}^{s}\right), M$ is the number of data sets, and $x^{\prime}{ }_{j}(i)$ is the $j$-th transformed variable of the fuzzy polynomial model of the $i$-th data set, subject to:

$$
\begin{aligned}
& \sum_{j=0}^{N_{\text {NR }}} a_{j}^{s} x^{\prime}{ }_{j}(i)+(1-h) \sum_{j=0}^{N_{\text {NR }}} a_{j}^{c}\left|x_{j}^{\prime}(i)\right| \geq y(i) \\
& \sum_{j=0}^{N_{N R}} a_{j}^{s} x^{\prime}{ }_{j}(i)+(1-h) \sum_{j=0}^{N_{N R}} a_{j}^{c}\left|x_{j}^{\prime}(i)\right| \leq y(i) \\
& a_{j}^{c} \geq 0, \quad a_{j}^{s} \in R, \quad x_{0}{ }^{\prime}(i)=1 \text { for all } i, \\
& 0 \leq h \leq 1, i=1,2, \cdots M, j=0,1,2, \cdots N_{N R} .
\end{aligned}
$$

$J$ in equation (9) is the total fuzziness of the regression model. The value of $h$ in equation (10) and equation (11) is between 0 and 1. $h$ refers to the degree to which the fuzzy linear model fits the given data sets, and is subjectively chosen by decision 
makers. Constraints (10) and (11) impose the restriction that the observation of the $i$ th data set $y(i)$ has at least $h$ degrees of belonging to $\tilde{y}(i)$ as $\mu_{\widetilde{y}(i)}(y(i)) \geq h(i=1,2, \cdots, M)$. Therefore, the objective of solving the linear programming problem (9-13) is to determine the fuzzy nonlinear parameters $\tilde{a}_{j}=\left(a_{j}^{c}, a_{j}^{s}\right)$ such that the total vagueness $J$ is minimized subject to $\mu_{\widetilde{y}(i)}(y(i)) \geq h(i=1,2, \cdots, M)$

\subsection{Fitness function}

In intelligent fuzzy regression, the fitness function is defined as:

$$
\text { fitness }_{j}=\frac{1-M A E_{j}}{\left(1+\exp \left(c_{1}\left(L_{j}-c_{2}\right)\right)\right)}
$$

where fitness $_{j}$ is the fitness value of the $j$-th individual, $L_{j}$ is the number of nodes of the $j$-th individual, $c_{1}$ and $c_{2}$ are both penalty terms, and the mean absolute error of the $j$-th individual $M A E_{j}$ is defined as the following formulation:

$$
M A E_{j}=100 \% \times \sqrt{\frac{1}{M} \sum_{k=1}^{M}\left|\frac{y(k)-F_{j}(x(k))}{y(k)}\right|},
$$

where $F_{j}$ is the fuzzy regression model represented by the $j$-th individual, $(y(k), x(k))=\left(y(k),\left(x_{1}(k), x_{2}(k), \ldots x_{N}(k)\right)\right)$ is the $k$-th training data set, $N$ is the number of variables of the training data set, and $M$ is the number of training data sets used for developing the fuzzy regression model. 
Equation (15) aims at fitting training data sets to the fuzzy regression model, and it avoids generating fuzzy regression models with too many insignificant terms. It is designed to find a balance between minimizing the number of terms and maximizing model accuracy, since a fuzzy regression model which contains many insignificant terms reduces its interpretation (Madar et al. 2005).

\subsection{Evolutionary operators}

Like other evolutionary algorithms, the two main evolutionary operators are crossover and mutation. The crossover operation produces a pair of offspring that inherit characteristics from both selected individuals by selecting a random node in each of the hierarchical tree structures of the individuals and exchanging the associated subexpressions of the hierarchical tree structures. For example, two individuals, $\theta_{i}$ and $\theta_{j}$, are selected for crossover; they are represented as Figure $2 \mathrm{a}$ and are shown as

follows:

$$
\begin{aligned}
& \theta_{i}=x_{1} * x_{2}+\left(-x_{3}\right) \\
& \theta_{j}=+x_{2}-\left(x_{3} * x_{4}\right)
\end{aligned}
$$

After the crossover operation, the individuals are represented as Figure $2 b$ and are shown as follows:

$$
\theta_{i}=x_{1} * x_{2}+\left(-x_{3}\right)
$$


$\theta_{j}=+x_{2}-\left(x_{3} * x_{4}\right)$

Because of the dynamic representation used in GP-FR, typically the parents are different in size, shape and content. The process of mapping the genotype onto the phenotype does not correspond to a one-to-one relationship. Therefore, the resulting offspring can be expressed by more than one different tree structure and some diversification of the population is allowed.

Mutation is performed by randomly selecting a node that is an internal or terminal node and replacing the associated sub-expression with a randomly generated sub-expression. For example, an individual $\theta_{i}$ (as shown in Figure 3) is selected for mutation:

$$
\theta_{i}=\left(x_{1}-x_{2}\right)+\left(x_{3} * x_{4}\right)
$$

As shown in Figure 3, the individual is mutated by replacing a minus in the node with a multiplier. After the mutation has been performed, the individual became:

$$
\theta_{i}=\left(x_{1}-x_{2}\right)+\left(x_{3}-x_{4}\right)
$$


1-st individual: $\theta_{i}$

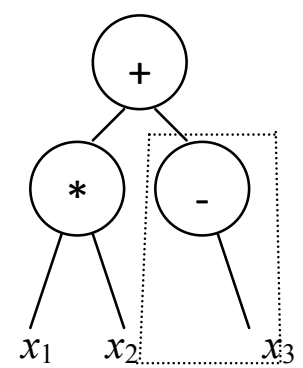

2-nd individual: $\theta_{j}$

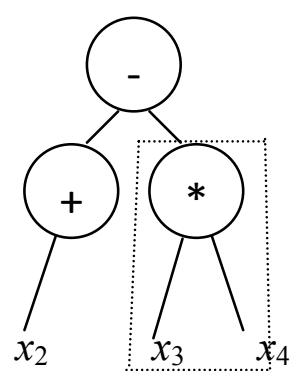

Figure 2 (a) The individuals $\theta_{\mathrm{i}}$ and $\theta_{j}$ prior to crossover

1-st individual: $\theta_{i}$,

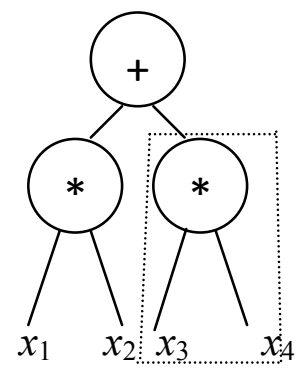

2-nd individual: $\theta_{j}$,

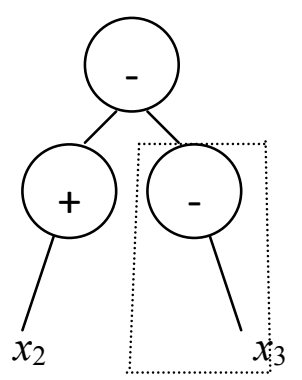

Figure 2 (b) The individuals $\theta_{\mathrm{i}}$ ' and $\theta_{\mathrm{j}}$ ' after crossover has been performed

The individual $\theta_{k}$ before the mutation

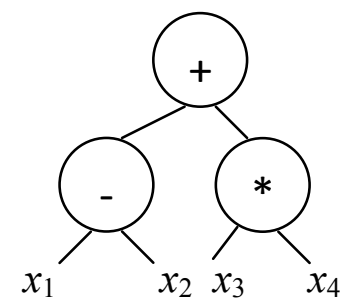

The individual $\theta_{k}$ ' before the mutation

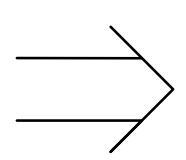

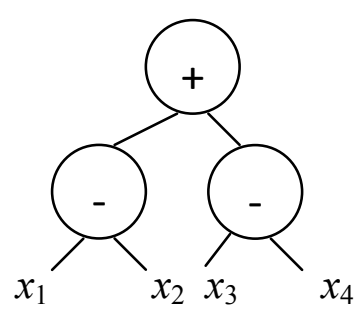

Figure 3 Individual produced by the mutation 


\subsection{Selection and convergence}

After performing crossover and mutation, individuals from the current population $\Omega(t)$ with relatively better fitness are selected to serve as parents for the next generation $\Omega(t+1)$. The approach of a roulette-wheel, which is one of the most common selection methods used for selecting individuals to perform reproduction operations in evolutionary algorithms (Goldberg 1989), is used in intelligent fuzzy regression. Regarding the $j^{\text {th }}$ individual, its fitness is assigned a value, fitness ${ }_{j}$, and the selection probability value, prob $_{j}$, is defined as:

$$
\operatorname{prob}_{j}=\frac{\text { fitness }_{j}}{\sum_{j=1}^{P O P} \text { fitness }_{j}}
$$

where $P O P$ is the population size of the intelligent fuzzy regression. Equation (20) shows that the individual with a larger fitness value has a higher probability of being selected.

After the selection, the population evolves and improves iteratively until a stopping condition is met. In the intelligent fuzzy regression, the stopping criterion is met when the number of generations is equal to a pre-defined number of generations. Otherwise, the intelligent fuzzy regression goes on to the next iteration. 


\section{An Illustration Example}

\subsection{Mobile phone design}

The example of mobile phone design is used to illustrate the intelligent fuzzy regression approach to modeling the relationships between affective responses and design variables defined in equation (2) in Section 2. In the highly competitive market of mobile phones, the product designers provide the consumers with various styles for different brands and different product series. To capture the trend of the recent market in mobile phones, 32 recent mobile phones of various brands including Nokia, Sony Ericsson and Motorola were selected and are shown in Figures 1 and 2. Morphological analysis was used to extract representative elements of mobile phones as numerical data sets, in which both the shape profiles and the product components of the mobile phones were used. Table 1 shows the 9 representative elements "top shape", "bottom shape", "side shape", "function button shape", "number button style", "length width ratio", "thickness", "layout" and "Border and frame", which are denoted as $x_{1}, x_{2}, x_{3}, x_{4}, x_{5}, x_{6}, x_{7}, x_{8}$ and $x_{9}$ respectively. They were identified from the 32 mobile phone samples. Each representative element has various types of form variations, which ranged from 3 to 6 .

The four most representative affective responses for mobile phone design, “simple - complex" (S-C), "unique - general" (U-G), "high-tech - classic" (H-C), 
and "handy - bulky" (H-B) (Lai et al. 2004), were collected from the 14 image word pairs for micro-electronic products (Chuang and Ma 1999), and they were used for evaluating the images values of the mobile phones. A survey was conducted using an online questionnaire to ask about the appearance of mobile phones on the $\mathrm{S}-\mathrm{C}, \mathrm{U}-\mathrm{G}$, $\mathrm{H}-\mathrm{C}$, and H-B responses, in which their degrees of image values are denoted as $y_{1}, y_{2}$, $y_{3}$ and $y_{4}$ respectively. The ranking scale ranges from 1 to 5 in which 1 is the smallest and 5 is the largest. Both front and side views of mobile phones were used for evaluating the product images since both front and side views of mobile phones influence the product image of mobile phones. Figure 3 shows one of the illustrations of the mobile phones in the survey in which 32 illustrations were given. Table 2 shows the morphological matrix of the 32 mobile phones samples based on the 9 representative elements. Also, it shows the means of the affective responses $\mathrm{S}-\mathrm{C}, \mathrm{U}-\mathrm{G}$, $\mathrm{H}-\mathrm{C}$, and $\mathrm{H}-\mathrm{B}$ with respect to 34 interviewers.

\subsection{Model development}

The objective of modeling is to relate the design variables $x_{1}, x_{2}, x_{3}, x_{4}, x_{5}, x_{6}, x_{7}, x_{8}$ and $x_{9}$ to one of the affective responess $y_{1}, y_{2}, y_{3}$ and $y_{4}$. The modeling results based on intelligent fuzzy regression are compared with those based on statistical regression (Seber 2003), Peters' fuzzy regression (Peters 1994) and Takagi's fuzzy regression (Takagi and Sugeno 1985). Evaluation of the effectiveness of the models is carried out 
by investigating the mean of training errors as shown below:

$$
\operatorname{Re}=\frac{1}{M} \sum_{i=1}^{M} \frac{\left|y_{k}(i)-P_{k}\left(x_{1}(i), x_{2}(i), \ldots, x_{9}(i)\right)\right|}{y_{k}(i)} \times 100 \%
$$

In equation (21) above, $M$ is the number of data sets; $y_{k}(i)$ is the $k$-th affective response of the $i$-th data set; $x_{1}(i), x_{2}(i), \ldots$ and $x_{9}(i)$ are the $i$-th data set for the design variables; and $P_{k}\left(x_{1}(i), x_{2}(i), x_{3}(i), \ldots, x_{9}(i)\right)$ is the prediction of the $k$-th affective response for the $i$-th data.

Using the 32 experimental data sets and their results shown in Table 2, the proposed intelligent fuzzy regression was implemented using Matlab to generate models to relate the image values $\left(y_{1}, y_{2}, y_{3}, y_{4}\right)$ and the design values $\left(x_{1}, x_{2}, x_{3}, \ldots\right.$ $x_{9}$ ). The parameters used in the intelligent fuzzy regression were set as shown in Table 3 with reference to (Madar et al. 2005). Since intelligent fuzzy regression is a stochastic method, different results will be obtained from different runs. To evaluate its overall performance, 30 runs on intelligent fuzzy regression were carried out, and the mean of the 30 runs was calculated. The models developed for the four affective responses $\mathrm{S}-\mathrm{C}, \mathrm{U}-\mathrm{G}, \mathrm{H}-\mathrm{C}$, and $\mathrm{H}-\mathrm{B}$ by using the four methods, and the training errors (Re) of the developed models are summarized in Table 4. It shows that the Re of the proposed intelligent fuzzy regression is smaller than those of the statistical regression, Takagi’s fuzzy regression and Peter fuzzy regression. This indicates that the proposed intelligent fuzzy regression can fit the data sets with the smallest mean errors. 
To further validate the modeling performance of the intelligent fuzzy regression, two data sets were randomly selected from the 32 data sets, as shown in Table 2, as testing data sets and the remaining 30 data sets were used to develop an intelligent fuzzy regression model, a statistical regression model, a Takagi’s fuzzy regression model and Peters' fuzzy regression model. Their prediction errors were calculated. The validations were repeated 32 times. Because intelligent fuzzy regression is a stochastic algorithm, we ran the GP-FR 30 times in each validation test, and the mean of the 30 runs was calculated. Results of the 32 validation tests for models of S-C, U-G, H-C and H-B are shown in Figures 4, 5, 6 and 7 respectively. The results of the statistical regression, Takagi's fuzzy regression, Peters' fuzzy regression and intelligent fuzzy regression are shown as circle dot lines "o-", star dot lines "*-", plus dot lines "+-" and solid lines "--" respectively. It can be seen that the prediction errors of the intelligent fuzzy regression, for all the tests, are usually the smallest. Table 5 summarizes the means and variances of the prediction errors of the S-C, U-G, H-C and H-B for the four methods respectively. From the table, it can be seen that intelligent fuzzy regression yields the smallest means of prediction errors and variances of prediction errors for all S-C, U-G, H-C and H-B.

\subsection{Optimization of affective design}

In optimization of affective design of the mobile phones, it is necessary to determine a setting of design variables so as to maximize the four affective responses, S-C, U-G, 
$\mathrm{H}-\mathrm{C}$ and $\mathrm{H}-\mathrm{B}$. To determine the optimal design variables, the multi-objective function is formulated by maximizing the four affective responses, S-C, U-G, H-C and H-B. Because the proposed intelligent fuzzy regression can achieve the best affective models among the four methods, the models developed by the proposed intelligent fuzzy regression are used and the multi-objective function is formulated by:

$\max \left\{\begin{aligned} y_{1}= & (0.04529,0.6639)+(2.0400,0.0453) \cdot\left(\mathrm{x}_{9}+\mathrm{x}_{6} \cdot \mathrm{x}_{7}\right) \\ y_{2}= & (2.7266,0.0025) \cdot \mathrm{x}_{5} \cdot \mathrm{x}_{8}+(-0.1769,1.1952) \cdot \mathrm{x}_{8}+(1.0102,0.0023) \\ y_{3}= & (1.1201,0) \cdot \mathrm{x}_{6}{ }^{2} \cdot \mathrm{x}_{5}+(-0.0206,0.3143) \cdot \mathrm{x}_{6}+(1.0444,0) \cdot \mathrm{x}_{2}+(0.0366,0) \\ y_{4}= & (3.6920,0) \cdot \mathrm{x}_{4}+(-0.1531,0) \cdot \mathrm{x}_{8}+(0.0165,0.2423) \cdot \mathrm{x}_{8}{ }^{2}+ \\ & (-0.5189,0) \cdot\left(\mathrm{x}_{8}+\mathrm{x}_{7}{ }^{2}+\mathrm{x}_{4} \cdot \mathrm{x}_{7}\right)\end{aligned}\right.$
subject to: $x_{1}, x_{2}, x_{3}, x_{4}, x_{5}, x_{9} \in\{1,2, \ldots, 6\} ;$

$$
\begin{aligned}
& x_{6}, x_{8} \in\{1,2,3\} ; \\
& x_{7} \in\{1,2,3,4\}
\end{aligned}
$$

(21) is a Pareto-based multi-objective problem which can be solved by the multiobjective genetic algorithm richly represented in the literature for solving multiobjective problems (Knowles and Corne, 2000; Zitzler and Thiele, 1999). Therefore, GA was used in this research. The GA optimization model aims at minimizing the objective function (21) from which an optimal design variables $\left(x_{1}, x_{2}, x_{3}, x_{4}, x_{5}, x_{6}, x_{7}\right.$, $x_{8}$ and $x_{9}$ ) setting can be obtained to achieve the maximum of $y_{1}, y_{2}, y_{3}$ and $y_{4}$. The detailed description of the multi-objective genetic algorithm, which is not the contribution or scope of this paper, is not presented in this paper. The operations and the parameters used in the genetic algorithm can be referred to (Chan et al. 2009). The optimal design variables are found as:

$$
x_{1}=3, x_{2}=2, x_{3}=6, x_{4}=2, x_{5}=1, x_{6}=2, x_{7}=4, x_{8}=3 \text { and } x_{9}=5
$$

The optimal affective responses can be achieved on the mobile phone based on optimal design variables. 


\section{Conclusion}

Existing modeling methods which relate customers' affective responses and the design variables of a new product have not addressed the development of explicit models which represents the nonlinearity or fuzziness inherent in such relationships. In this paper, we have proposed an intelligent fuzzy regression to generate models for relating design variables to affective responses in which both nonlinearity and fuzziness are considered. In order to develop a methodology which is capable of addressing both fuzziness and nonlinearity in fuzzy regression, we employed the evolutionary algorithm to first construct branches of a tree which represents the nonlinear structures of the model. Then we used the fuzzy regression algorithm to calculate the fuzzy coefficients of the model. The resulting model is explicit, and consists of fuzzy nonlinear terms in relating affective responses to design variables.

A case study of the affective product design of mobile phones is used to illustrate the proposed method. To validate this intelligent fuzzy regression approach in modeling the relationship between affective responses to design variables, it has been applied for generating models of affective product design of mobile phones. The four affective responses of customers and nine design variables in mobile phones were considered. It has been compared with the other commonly used explicit modeling methods, statistical regression and two fuzzy regression methods. The results show 
that models with the smallest training errors are generated by the intelligent fuzzy regression rather than the ones generated by the other methods. This indicates that the intelligent fuzzy regression approach is more capable of modeling the survey data sets, which are fuzzy and nonlinear. The validation results show that the smallest prediction errors and errors in variance are also achieved by intelligent fuzzy regression rather than by other methods. Better results were achieved and can be explained by the fact that nonlinearity and fuzziness were taken into consideration using the intelligent fuzzy regression approach, which is not represented in commonly used existing methods.

There is no evidence to show that stochastic methods outperform the others. In the future, an evaluation of the performance of the fuzzy regression based polynomial modeling will be implemented using other stochastic methods like particles swarm optimization and immune optimization algorithm. A more appropriate and effective modeling method is expected to be reported in the future.

\section{Reference}

Artacho M.A., Ballester A. and Alcantara E. (2009) Analysis of the impact of slight changes in product formal attributes on user's emotions and configuration of an emotional space for successful design, Journal of Engineering Design, 2009. 
Barnes C. and Lillford S.P. (2009) Decision support for the design of affective products, Journal of Engineering Design, 20(5), 477-492.

Chan K.Y., Kwong C.K. and Tsim Y.C. (2009) Modelling and optimization of fluid dispensing for electronic packaging using neural fuzzy networks and genetic algorithms, Engineering Applications of Artificial Intelligence, 2009.

Chen C.H., Khoo L.P. and Yan W. (2006) An investigation into affective design using sorting technique and Kohonen self-organizing map, Advances in Engineering Software, 37, 334-349.

Chuang M.C. and Ma Y.C. (1999). Expressing the expected product images in product design of micro-electronic products. International Journal of Industrial Ergonomics, 27(4), 233-245

Cross N (2000). Engineering design methods: Strategies for product design $\left(3^{\text {rd }} \mathrm{ed}\right)$. Chichester, UK: Wiley.

Eggink W. (2009). A practical approach to teaching abstract product design issues, Journal of Engineering Design, 20(5), 511-521.

Girard S. and Johnson H. (2009). Developing affective educational software products: Soremo, a new method for capturing emotional states. Journal of Engineering Design, 20(5), 493-510.

Desmet, P.M.A., 2002. Designing emotions. Delft, The Netherlands: Delft University 
of Technology.

Diener, E. and Lucas, R.E., 2000. Subjective emotional well-being. In:M. Lewis and J.M. Haviland-Jones, eds. Handbook of emotions. 2nd ed. NewYork: The Guilford Press, 325-337.

Friedman, J.H. (1991) Multivariate Adaptive Regression Splines, The Annals of Statistics, 19(1), pp. 1-141.

Goldberg, D.E. (1989) Genetic Algorithms in Search, Optimization and Machine Learning. United States of America: Addison Wesley Longman, Inc.

Gu Z., Tang M.X. and Frazer J.H. (2006), Capturing aesthetic intention during interactive evolution, Computer-Aided Design, 38, 224-237.

Han S.H. and Hong S.W. (2003), A systematic approach for computing user satisfaction with product design, Ergonomics, 46(13), 1441-1461.

Han S.H., Yun M.H., Kim K., and Kwahk J. (2000), Evolution of product usability: development and validation of usability dimensions and design elements based on empirical models, International Journal of Industrial Ergonomics, 26, 477-488.

Hsiao, S.W. and Liu, M.C., (2002). A morphing method for shape generation and image prediction in product design. Design Studies, 23 (5), 497-513.

Hsiao, S.W. and Tsai H.C. (2005), Applying a hybrid approach based on fuzzy neural network and genetic algorithm to product form design, International Journal of 
Industrial Ergonomics, 35, 411-428.

Jiao, J. (2006) A Kansei mining system for affective design, Expert Systems with Applications, 30, 658-673.

Jindo T. and Hirasago K. (1997) Application studies to car interior of Kansei engineering, International Journal of Industrial Ergonomics 19, 105-114.

Jordan, P.W., 2000. Designing pleasurable products: an introduction to the new human factors. London: Taylor\&Francis.

Kesteren I., Bruijn S. and Stappers P.J. (2008) Evaluation of materials selection activites in user-centred design projects, Journal of Engineering Design, 19(5), 417-429.

Khalid H.M. (2001) Towards affective collaborative design. In M.J. Smith, G. Salvendy, D. Harris, and R.J. Koubek, Usability Evaluation and Interface Design. Proceedings of HCI International 2001 (vol. 1). Mahwah, NJ: Lawence Erlbaum.

Kim K.J., Moskowitz H. and Koksalan M. (1996) Fuzzy versus statistical linear regression, European Journal of Operational Research, 92, 417-434

Kouprie M. and Visser F.S. (2009) A framework for empathy in design: stepping into and out of the user's life, Journal of Engineering Design, 20(5), 437-448.

Koza, J. (1992) Genetic Programming: On the Programming of Computers by Means of Natural Evolution, MIT Press: Cambridge. 
Knowles, J.D., Corne, D.W. (2000) Approximating the non-dominated front using the pareto archived evolution strategy. Evolutionary Computation, 8, 149-172.

Koza, J., 1994. Genetic Programming II: automatic discovery of reusable programs, MIT Press.

Kuang J. and Jiang P. 2008, Product platform design for a product family based on Kansei engineering, Journal of Engineering Design.

Lai H.H., Lin Y.C. and Yeh C.H. (2004) Form design of product image using grey relational analysis and neural network models. Computers \& Operations Research, 32(10), 2689-2711.

Lau, T.W., Hui C.L., Ng S.F. and Chan C.C. (2006) A new fuzzy approach to improve fashion product development, Computers in Industry, 57, 82-92.

Madar, J., Abonyi, J. and Szeifert, F., (2005) Genetic programming for the identification of nonlinear input - output models, Industrial and Engineering Chemistry Research. 44, $3178-3186$.

Mugge R., Schoormans J.P.L. and Schifferstein N.J. (2009) Emotional bonding with personalized products, Journal of Engineering Design, 20(5), 467-476.

Nagamachi M. (1995) Kansei Engineering: A new ergonomic consumer-oriented technology for product development, 15, 3-11.

Nurkka P., Kujala S. and Kemppainen K. (2009) Capturing user's perceptions of 
valuable experience and meaning, Journal of Engineering Design, 20(5), 449463.

Nikolaev, N. I. and H. Iba (2001) Accelerated Genetic Programming of Polynomials. Genetic Programming and Evolvable Machines, 2, 231-257.

Norman, D.A., 2004. Emotional design: why we love (or hate) everyday things. NewYork: Basic Books.

Park, J. and Han S.H., (2004) A fuzzy rule-based approach to modeling affective user satisfaction towards office chair design, International Journal of Industrial Ergonomics, 34, 31-47.

Peters G. (1994) Fuzzy linear regression with fuzzy intervals, Fuzzy Sets and Systems, 63, 45-55.

Petiot J.F. and Grognet S. (2006) Product design: a vectors field-based approach for preference modeling, Journal of Engineering Design, 17(3), 217-233.

Seber G.A.F. (2003), Linear regression analysis, Wiley.

Shimizu Y. and Jindo Y. (1995) A fuzzy logic analysis method for evaluation human sensitivities, International Journal of Industrial Ergonomics 15, 39-47.

Tanoue C., Ishizaka K., and Nagamachi M. (1997) Kansei engineering: a study on perception of vehicle interior image, International Journal of Industrial Ergonomics 19, 115-128. 
Takagi T. and Sugeno M. (1985) Fuzzy identification of systems and its application to modeling and control. IEEE Transactions on Systems, Man and Cybernetics 15(1), 116-132.

Tanaka H., Uejima S. and Asai K. (1982) Linear regression analysis with fuzzy model. IEEE Transactions on Systems, Man, and Cybernetics 12, 903-907.

Tanaka H. and Watada J. (1988) Possibilistic linear systems and their application to the linear regression model. Fuzzy Sets and Systems 272, 275-289.

Yang S., Nagamachi M. and Lee S. (1999) Rule based inference model for the Kansei engineering system. International Journal of Industrial Ergonomics 24, 459-471.

You H., Taebeum R.Y.U., Kyunghee O.H., Yun M.H. and Kim K.J. (2006) Development of customer satisfaction models for automotive interior materials. International Journal of Industrial Ergonomics 36, 323-330.

Zitzler E. and Thiele L. (1999) Multiobjective evolutionary algorithms: a comparative case study and the strength pareto approach. IEEE Transactions on Evolutionary Computation 3(4), 257-271. 


\section{Appendix}

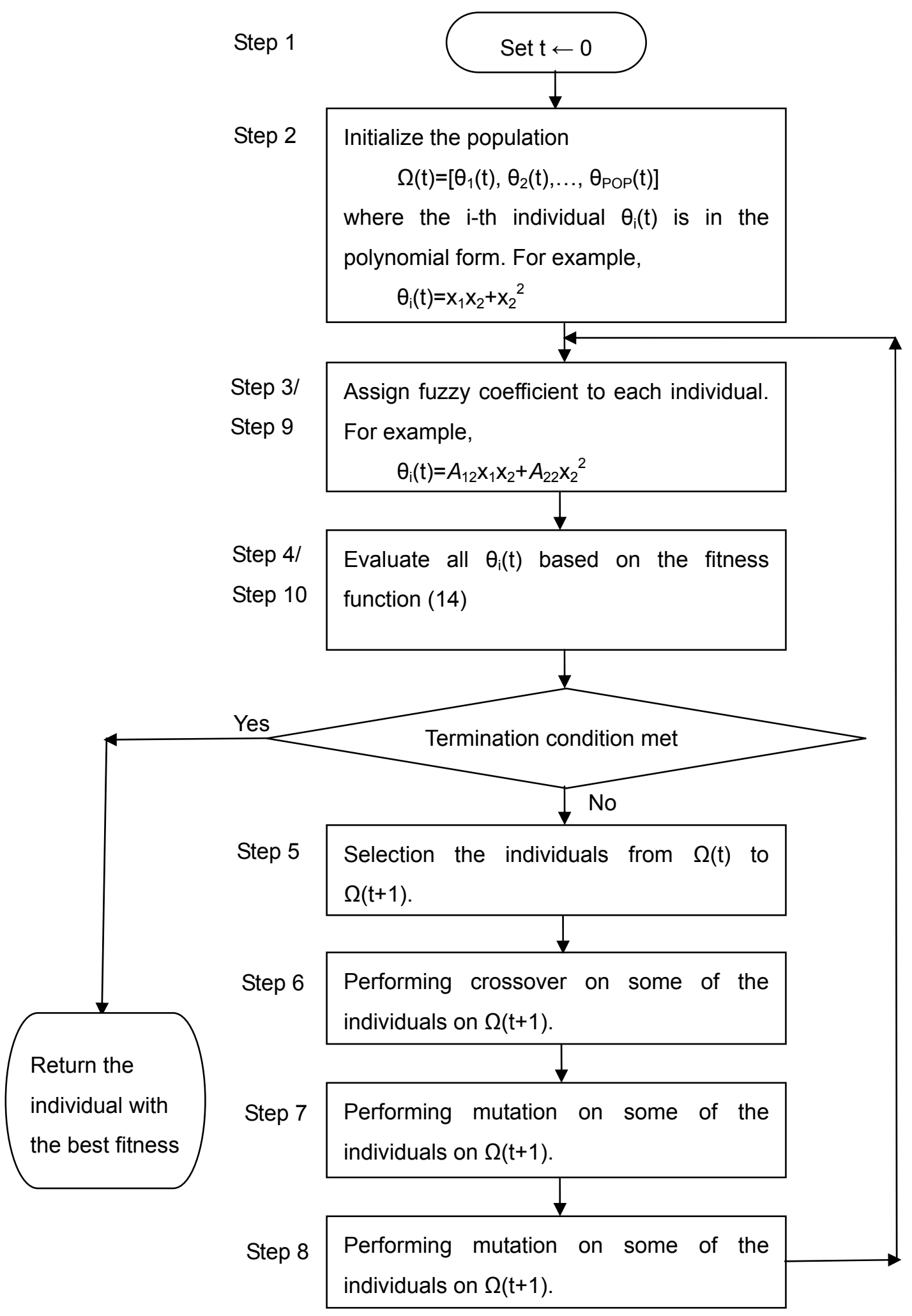

Figure 1 The flowchart of the intelligent fuzzy regression 


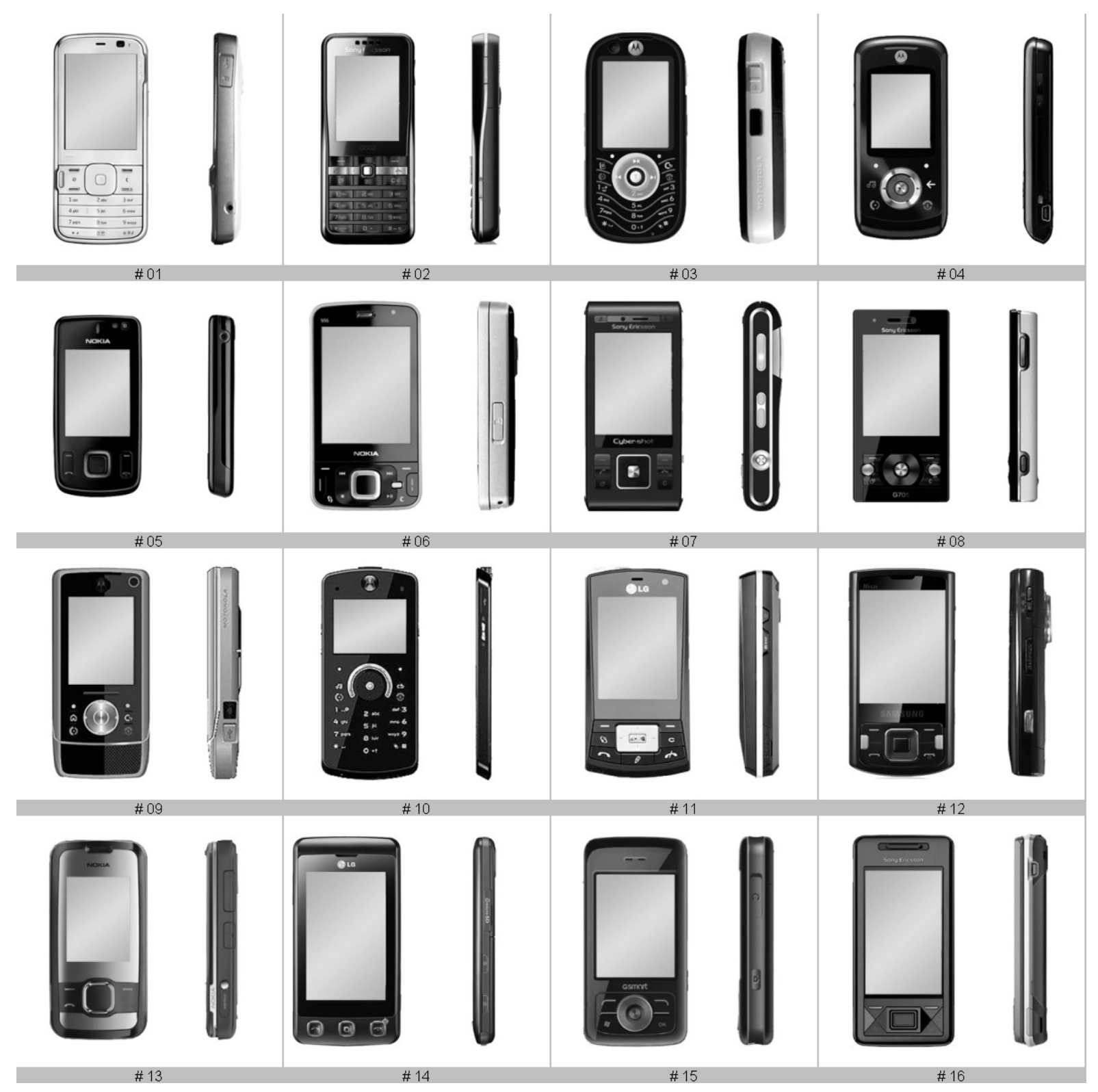

Figure 1 The 32 representative mobile phone samples 


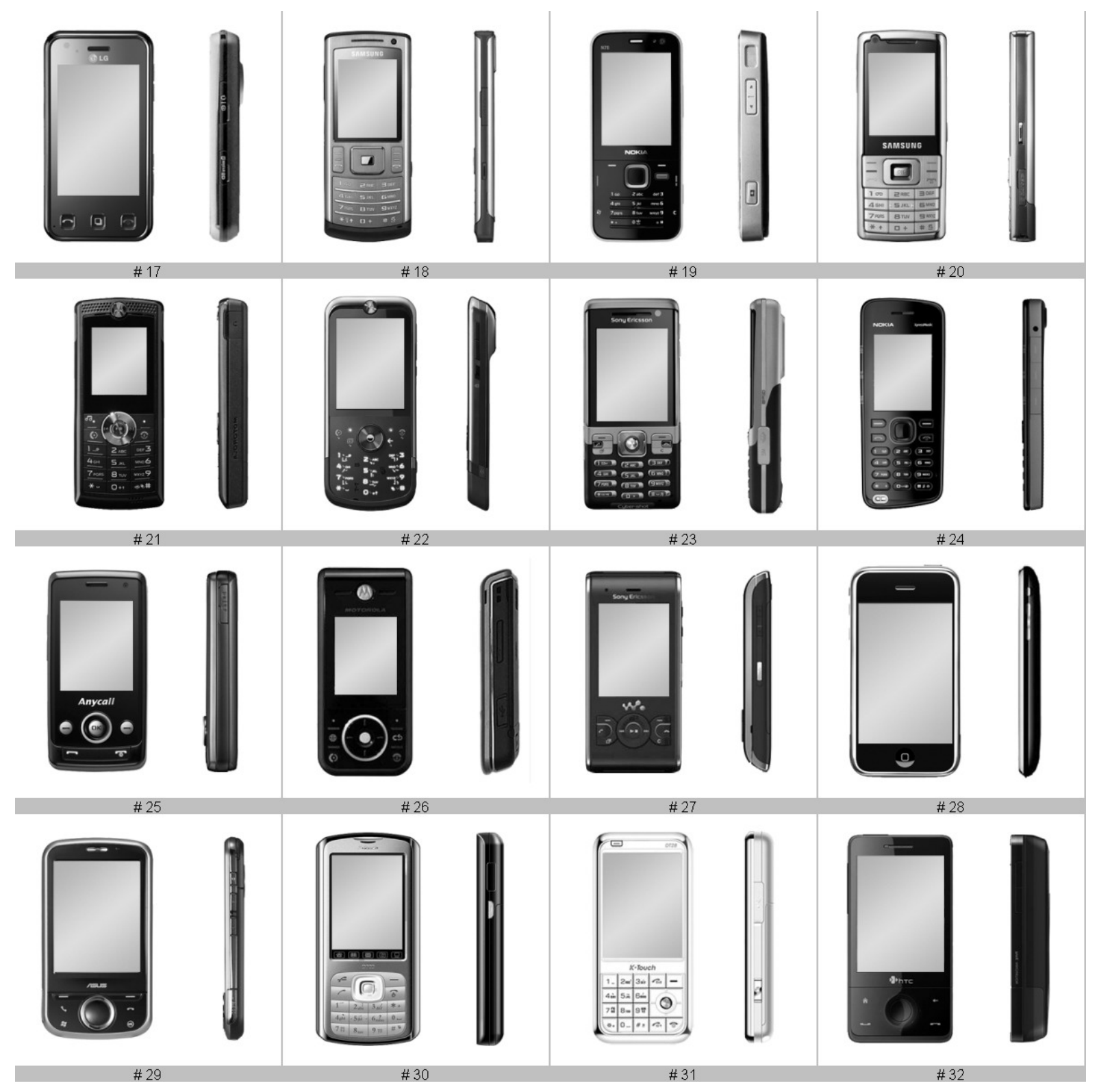

Figure 2 The 32 representative mobile phone samples (continued) 

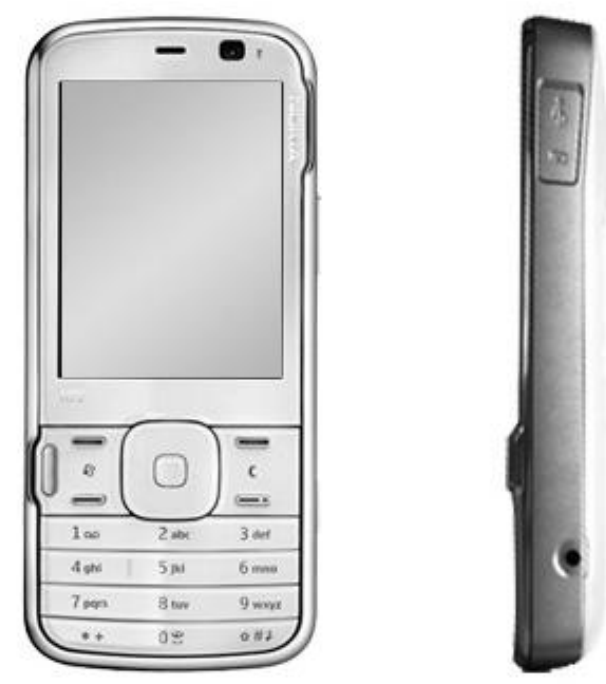

Does the shape feel?

\begin{tabular}{|c|c|c|c|c|c|c|}
\hline & & 1 & 2 & 3 & 4 & 5 \\
\hline $1^{*}$ & $\begin{array}{l}\text { simple or complex? } \\
(\text { simple }=1, \text { complex }=5 \text { ) }\end{array}$ & 0 & 0 & 0 & 0 & 0 \\
\hline $2^{*}$ & $\begin{array}{l}\text { unique or general? } \\
\text { (unique }=1 \text {, general =5) }\end{array}$ & 0 & 0 & 0 & 0 & 0 \\
\hline $3^{*}$ & $\begin{array}{l}\text { hi-tech or classic? } \\
\text { (hi-tech }=1, \text { classic }=5 \text { ) }\end{array}$ & 0 & 0 & 0 & 0 & 0 \\
\hline $4^{*}$ & $\begin{array}{l}\text { handy or bulky? } \\
\text { (handy }=1 \text {, bulky =5) }\end{array}$ & 0 & 0 & 0 & 0 & 0 \\
\hline
\end{tabular}

Figure 3 The format of the questionnaires for each mobile phone sample 


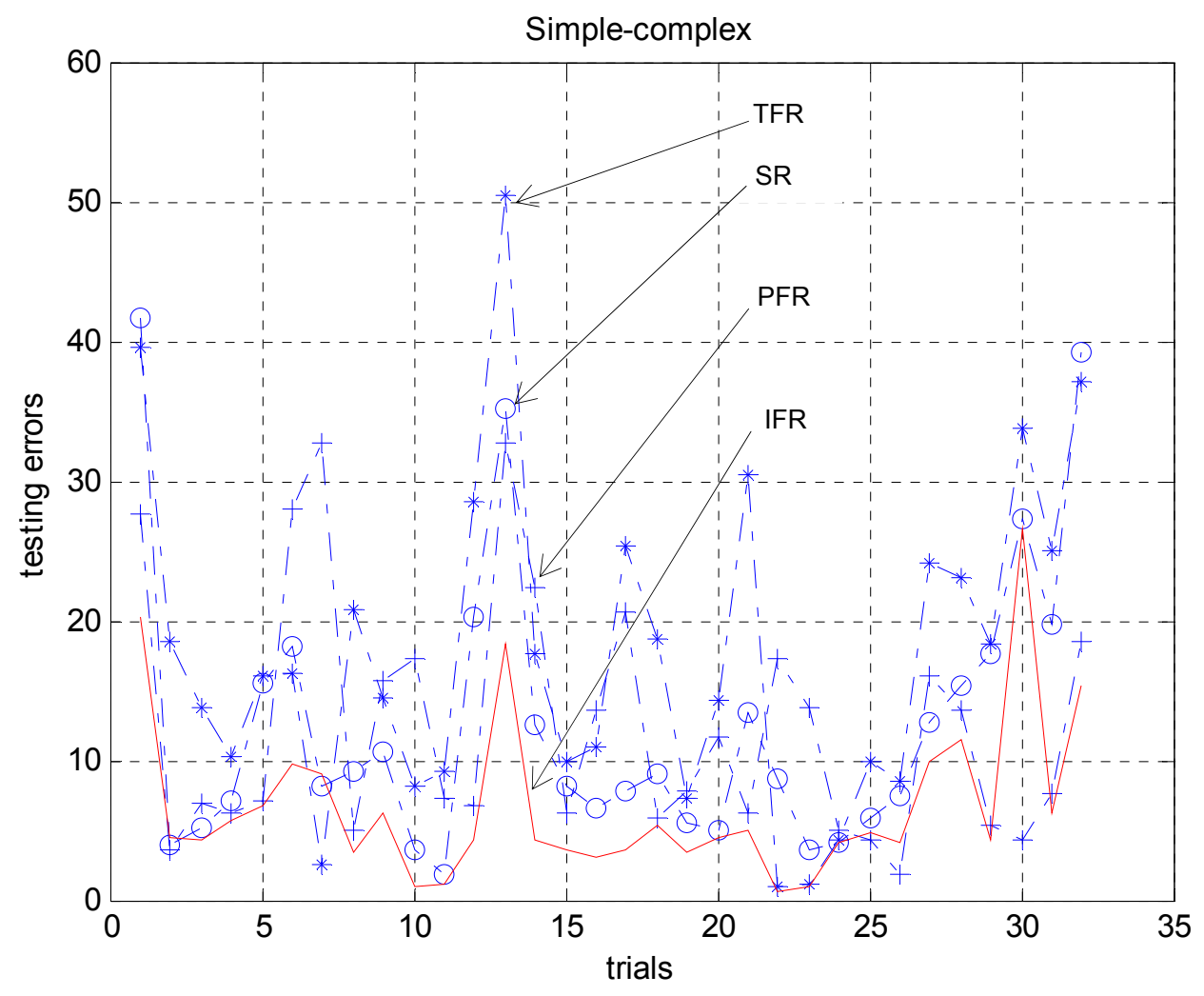

Figure 4 Validation results of the models for S-C 


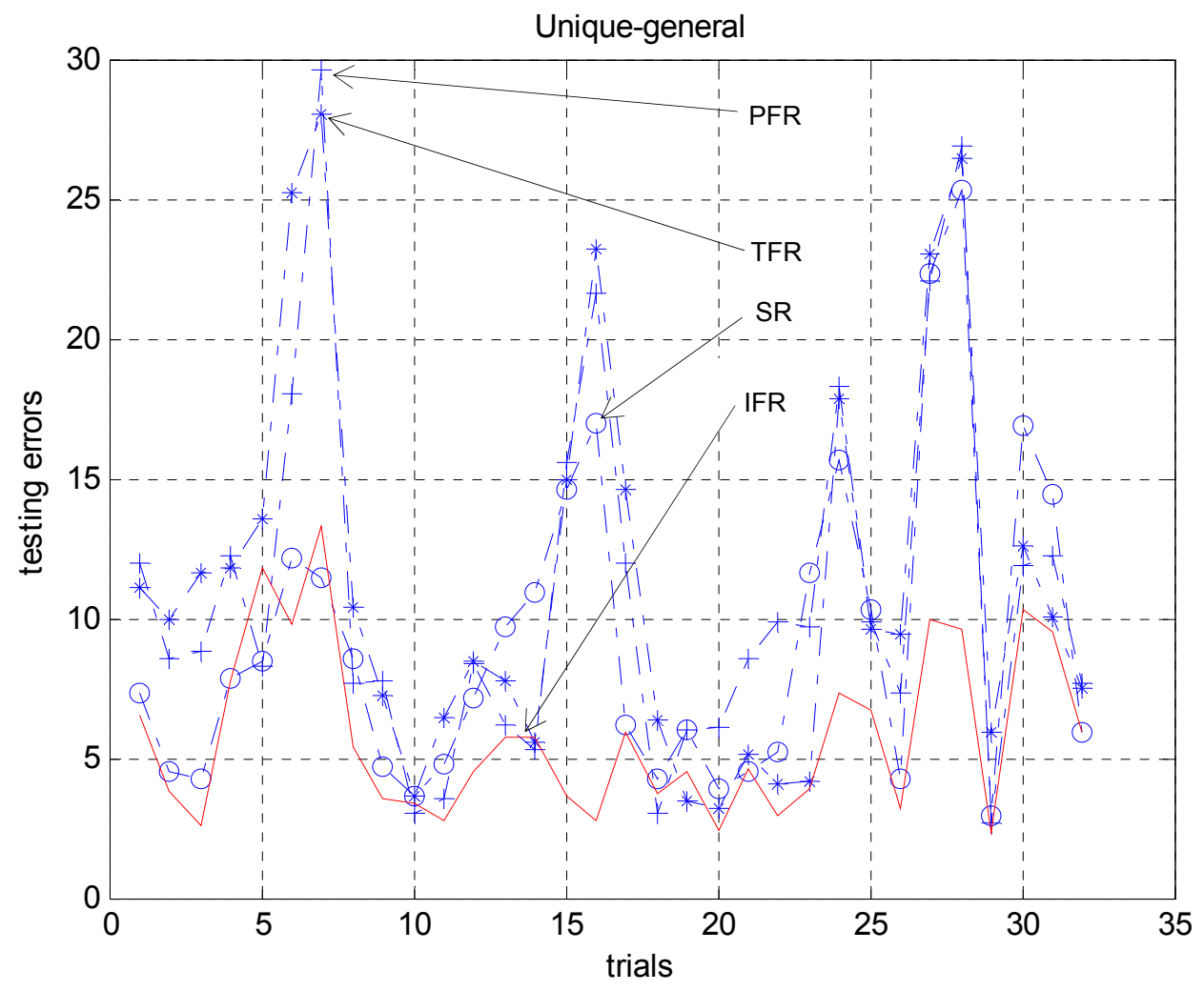

Figure 5 Validation results of the models for $U-G$ 


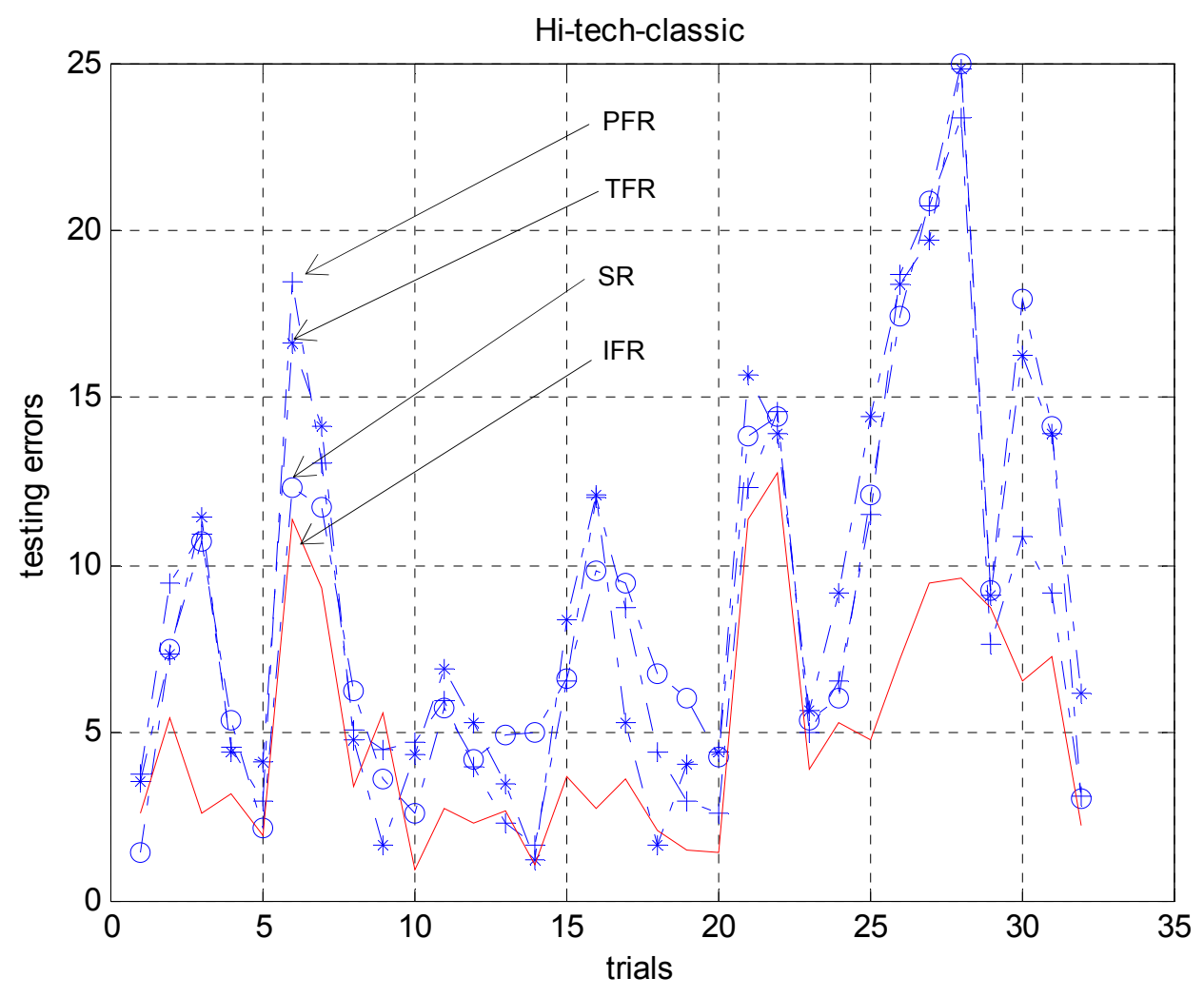

Figure 6 Validation results of the models for $\mathrm{H}-\mathrm{C}$ 


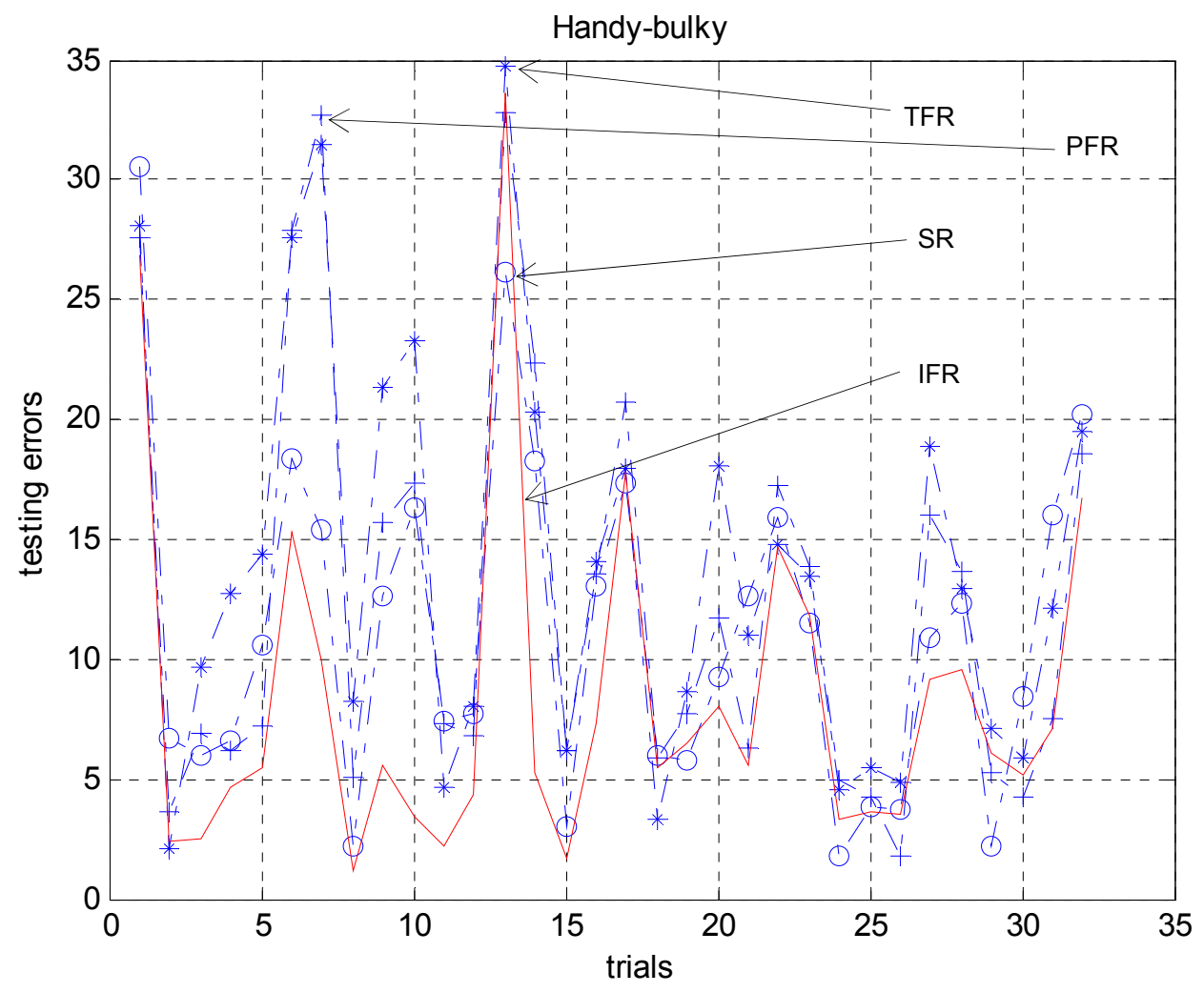

Figure 7 Validation results of the models for $\mathrm{H}-\mathrm{B}$ 
Table 1 Morphological analysis on the 32 representative mobile phone samples

\begin{tabular}{|c|c|c|c|c|c|c|c|}
\hline & Elements & Type 1 & Type 2 & Type 3 & Type 4 & Type 5 & Type 6 \\
\hline 1 & $\begin{array}{c}\text { Top Shape } \\
\left(x_{1}\right)\end{array}$ & $\begin{array}{l}\text { Line ard } \\
\text { no fillet }\end{array}$ & $\begin{array}{l}\text { Arc ard } \\
\text { no fillet }\end{array}$ & $\begin{array}{c}\text { Line ard } \\
\text { small fillet }\end{array}$ & Arc ard & Irregular & Cure \\
\hline 2 & $\begin{array}{c}\text { Bottom Shape } \\
\qquad\left(I_{3}\right)\end{array}$ & \begin{tabular}{|l} 
\\
$\substack{\text { Linie ard } \\
\text { no filltat }}$
\end{tabular} & J__ J ard & $\underbrace{}_{\substack{\text { Line ard } \\
\text { small fillat }}}$ & Arc ard & Irregular & Cure \\
\hline 3 & $\begin{array}{l}\text { Side Shape } \\
\left(r_{3}\right)\end{array}$ & $\underset{\substack{\text { Traperidal } \\
\text { rear }}}{\text { D. }}$ & ( & Paralleb gasm & Bownd & $\bigcup_{\substack{\text { Traperid } \\
\text { form }}}$ & Polygoral \\
\hline 4 & $\begin{array}{c}\text { Furiction Button } \\
\text { Shape } \\
\left(r_{4}\right)\end{array}$ & Round & $\underbrace{0}_{\text {Square ard }}$ & Small equares & Large equare & Wide large & Other Shape \\
\hline 5 & $\begin{array}{c}\text { Number Euttors } \\
\text { Style } \\
\left(Y_{3}\right)\end{array}$ & \begin{tabular}{|l|l|l|} 
& & \\
& & \\
& & \\
& & \\
Ro gular grid \\
\end{tabular} & $\begin{array}{llllll} & & & \\
\end{array}$ & $\underbrace{}_{\text {Bars }} \equiv$ & One piros & Other style & $\begin{array}{l}\text { No Numbert } \\
\text { buttents }\end{array}$ \\
\hline 6 & $\begin{array}{l}\text { Langth-wid th ratio } \\
\qquad\left(I_{6}\right)\end{array}$ & $16: 9$ & $2: 1$ & $5: 2$ & & & \\
\hline 7 & $\begin{array}{c}\text { Thickntass } \\
\left(r_{7}\right)\end{array}$ & $\leqq 10 \mathrm{~mm}$ & $11.14 \mathrm{~mm}$ & $15.18 \mathrm{~mm}$ & $\$ 19 \mathrm{~mm}$ & & \\
\hline 8 & $\begin{array}{l}\text { Layout } \\
\qquad\left(r_{3}\right)\end{array}$ & \begin{tabular}{|l|l|}
\multicolumn{1}{|l|}{} \\
\\
\end{tabular} & $\underbrace{}_{\text {Slide }}$ & $\underline{\underline{\square(0 \square}}$ & Other Layout & & \\
\hline 9 & $\begin{array}{l}\text { Border or frame } \\
\left(r_{9}\right)\end{array}$ & Narrow & Wide & 3 sided & 2 sided & 1 Sided & No borders \\
\hline
\end{tabular}


Table 2 Form design matrix of 32 mobile phone samples

\begin{tabular}{|c|c|c|c|c|c|c|c|c|c|c|c|c|c|}
\hline $\begin{array}{l}\text { Phone } \\
\text { no. }\end{array}$ & $\mathbf{A}_{1}$ & $\mathbf{A}_{2}$ & $\mathbf{A}_{3}$ & $\mathbf{A}_{4}$ & $\mathbf{A}_{5}$ & $\mathbf{A}_{6}$ & $\mathbf{A}_{7}$ & $\mathbf{A}_{8}$ & $\mathbf{A}_{9}$ & S-C & U-G & H-C & H-B \\
\hline 1 & 3 & 3 & 1 & 3 & 2 & 2 & 3 & 1 & 1 & 1.85 & 3.62 & 2.97 & 2.56 \\
\hline 2 & 3 & 3 & 2 & 2 & 1 & 2 & 2 & 1 & 2 & 2.59 & 3.44 & 3.15 & 2.79 \\
\hline 3 & 6 & 6 & 1 & 1 & 5 & 2 & 4 & 1 & 2 & 2.88 & 2.76 & 3.21 & 3.32 \\
\hline 4 & 4 & 4 & 3 & 1 & 6 & 2 & 2 & 2 & 2 & 2.41 & 2.65 & 2.88 & 2.59 \\
\hline 5 & 3 & 4 & 3 & 4 & 6 & 2 & 2 & 2 & 2 & 2.06 & 2.85 & 2.53 & 2.47 \\
\hline 6 & 3 & 3 & 1 & 5 & 6 & 1 & 3 & 2 & 1 & 2.71 & 2.41 & 2.15 & 3.18 \\
\hline 7 & 1 & 1 & 2 & 4 & 6 & 3 & 4 & 2 & 6 & 3.26 & 2.53 & 2.47 & 3.18 \\
\hline 8 & 1 & 1 & 1 & 2 & 6 & 2 & 2 & 2 & 6 & 2.79 & 2.74 & 2.50 & 2.71 \\
\hline 9 & 3 & 4 & 6 & 1 & 6 & 2 & 3 & 2 & 2 & 2.91 & 2.65 & 2.85 & 3.12 \\
\hline 10 & 4 & 4 & 3 & 6 & 4 & 3 & 2 & 1 & 2 & 2.65 & 2.82 & 3.00 & 2.15 \\
\hline 11 & 2 & 2 & 6 & 5 & 6 & 2 & 4 & 2 & 2 & 2.76 & 2.62 & 2.47 & 3.18 \\
\hline 12 & 2 & 2 & 6 & 3 & 6 & 2 & 3 & 2 & 4 & 2.71 & 2.56 & 2.41 & 3.38 \\
\hline 13 & 6 & 6 & 6 & 4 & 6 & 2 & 3 & 2 & 2 & 2.09 & 2.76 & 2.85 & 2.71 \\
\hline 14 & 4 & 4 & 2 & 6 & 6 & 1 & 2 & 3 & 3 & 2.21 & 2.09 & 2.09 & 1.94 \\
\hline 15 & 4 & 3 & 6 & 1 & 6 & 2 & 3 & 2 & 2 & 2.44 & 2.82 & 2.71 & 3.09 \\
\hline 16 & 3 & 3 & 6 & 5 & 6 & 2 & 3 & 2 & 1 & 2.62 & 2.15 & 2.35 & 2.94 \\
\hline 17 & 3 & 3 & 2 & 6 & 6 & 1 & 2 & 3 & 1 & 2.12 & 2.53 & 2.35 & 3.03 \\
\hline 18 & 2 & 4 & 6 & 5 & 2 & 3 & 1 & 1 & 5 & 2.50 & 3.38 & 2.97 & 2.59 \\
\hline 19 & 3 & 3 & 1 & 4 & 5 & 3 & 3 & 1 & 1 & 2.41 & 3.00 & 3.00 & 3.03 \\
\hline 20 & 4 & 4 & 6 & 5 & 1 & 3 & 2 & 1 & 1 & 2.68 & 3.68 & 3.53 & 3.06 \\
\hline 21 & 4 & 4 & 1 & 1 & 2 & 3 & 2 & 1 & 2 & 2.88 & 3.35 & 3.29 & 3.12 \\
\hline 22 & 6 & 4 & 3 & 1 & 4 & 3 & 2 & 1 & 2 & 2.88 & 2.94 & 2.97 & 2.97 \\
\hline 23 & 3 & 3 & 6 & 2 & 3 & 2 & 3 & 1 & 6 & 3.12 & 3.38 & 3.15 & 3.56 \\
\hline 24 & 5 & 5 & 1 & 4 & 3 & 3 & 2 & 1 & 1 & 2.50 & 2.85 & 3.24 & 2.62 \\
\hline 25 & 4 & 4 & 6 & 1 & 6 & 2 & 3 & 2 & 2 & 2.44 & 3.21 & 3.06 & 3.09 \\
\hline 26 & 3 & 6 & 5 & 1 & 6 & 3 & 3 & 2 & 2 & 2.68 & 2.97 & 2.85 & 3.32 \\
\hline 27 & 1 & 1 & 5 & 1 & 6 & 2 & 2 & 2 & 4 & 2.65 & 2.79 & 2.79 & 2.91 \\
\hline 28 & 3 & 3 & 4 & 1 & 6 & 1 & 2 & 3 & 2 & 2.00 & 1.91 & 1.91 & 2.53 \\
\hline 29 & 4 & 4 & 2 & 1 & 6 & 1 & 2 & 2 & 2 & 2.41 & 2.47 & 2.21 & 2.56 \\
\hline 30 & 4 & 4 & 4 & 5 & 2 & 2 & 3 & 1 & 2 & 3.26 & 3.15 & 2.82 & 3.03 \\
\hline 31 & 3 & 3 & 1 & 6 & 6 & 2 & 3 & 4 & 2 & 3.38 & 2.79 & 2.76 & 3.18 \\
\hline 32 & 3 & 3 & 1 & 1 & 6 & 2 & 3 & 2 & 1 & 2.32 & 2.62 & 2.56 & 3.50 \\
\hline
\end{tabular}


Table 3 GP parameters implemented in the GP-FR

\begin{tabular}{|c|c|}
\hline Population size & 50 \\
\hline Maximum number of evaluated & 5000 \\
\hline Generation gap & 0.9 \\
\hline Probability of crossover & 0.5 \\
\hline Probability of mutation & 0.5 \\
\hline Probability of changing terminal via & 0.25 \\
\hline non-terminal & $c_{1}=0.5$ and $c_{2}=30$ \\
\hline Penalty factors in the fitness function & \\
\hline (20) & 30 \\
\hline Maximum depth of tree & \\
\hline
\end{tabular}


Table 4 Training errors (Re in percentage) of the four modeling methods

\begin{tabular}{|c|c|c|c|}
\hline $\begin{array}{l}\text { Affective } \\
\text { responses }\end{array}$ & $\begin{array}{l}\text { Training } \\
\text { method }\end{array}$ & Trained models & $\begin{array}{c}\text { Training error } \\
(\%)\end{array}$ \\
\hline \multirow[t]{4}{*}{$\mathrm{S}-\mathrm{C}$} & SR & $\begin{array}{l}y=1.2798+0.2506 \cdot x_{1}-0.1986 \cdot x_{2}-0.0272 \cdot x_{3}-0.0010 \cdot x_{4}-0.4208 \cdot x_{5}+0.4547 \cdot x_{6}+ \\
0.6401 \cdot x_{7}+0.3634 \cdot x_{8}+0.2580 \cdot x_{9}\end{array}$ & 9.2081 \\
\hline & TFR & $\begin{array}{l}y=(1.2066,0)+(0.4963,0) \cdot x_{1}+(-0.5252,3.5191) \cdot x_{2}+(0.2057,0) \cdot x_{3}+ \\
(0.2182,0.9900) \cdot x_{4}+(-0.0123,0) \cdot x_{5}+(0.5136,0) \cdot x_{6}+(0.0680,0) \cdot x_{7}+(0.1819,0) \cdot x_{8}+ \\
(0.2863,0) \cdot x_{9}\end{array}$ & 11.836 \\
\hline & PFR & $\begin{array}{l}y=(0.8671,0.0747)+(0.1073,0.0252) \cdot x_{1}+(-0.04815,0.0257) \cdot x_{2}+(0.0166,0.1164) \cdot x_{3}+ \\
(0.0352,0.0409) \cdot x_{4}+(-0.0147,0.0035) \cdot x_{5}+(0.1358,0.0201) \cdot x_{6}+(0.1407,0.2719) \cdot x_{7}+ \\
(0.1597,0.0144) \cdot x_{8}+(0.2863,0.0089) \cdot x_{9}\end{array}$ & 9.2132 \\
\hline & IFR & $y=(0.04529,0.6639)+(2.0400,0.0453) \cdot\left(x_{9}+x_{6} \cdot x_{7}\right)$ & 0.091471 \\
\hline \multirow[t]{4}{*}{ U-G } & SR & $\begin{array}{l}y=3.3302-0.1971 \cdot x_{1}+0.1514 \cdot x_{2}+0.0480 \cdot x_{3}-0.1195 \cdot x_{4}-0.9145 \cdot x_{5}+0.2959 \cdot x_{6}+ \\
0.1916 \cdot x_{7}+0.0522 \cdot x_{8}-0.0106 \cdot x_{9}\end{array}$ & 8.3444 \\
\hline & TFR & $\begin{array}{l}y=(3.4331,0)+(-0.5917,0) \cdot x_{1}+(0.4612,0) \cdot x_{2}+(0.1273,0.3813) \cdot x_{3}+(-0.2291,0) \cdot x_{4}+ \\
(-1.1061,0) \cdot x_{5}+(0.3110,0) \cdot x_{6}+(0.4329,0) \cdot x_{7}+(-0.0143,2.9794) \cdot x_{8}+(0.0042,0) \cdot x_{9}\end{array}$ & 8.5260 \\
\hline & PFR & $\begin{array}{l}y=(3.7118,0)+(-0.1918,0.0091) \cdot x_{1}+(0.1403,0.0007) \cdot x_{2}+(0.0159,0) \cdot x_{3}+(- \\
0.0698,0) \cdot x_{4}+(-0.2007,0) \cdot x_{5}+(0.0893,0) \cdot x_{6}+(0.1284,0) \cdot x_{7}+(-0.0773,0.1393) \cdot x_{8}+(- \\
0.0038,0) \cdot x_{9}\end{array}$ & 7.6739 \\
\hline & IFR & $y=(2.7266,0.0025) \cdot x_{5} \cdot x_{8}+(-0.1769,1.1952) \cdot x_{8}+(1.0102,0.0023)$ & 0.07278 \\
\hline \multirow[t]{4}{*}{$\mathrm{H}-\mathrm{C}$} & SR & $\begin{array}{l}y=2.2971+0.1752 \cdot x_{1}+0.0767 \cdot x_{2}+0.0321 \cdot x_{3}-0.1197 \cdot x_{4}-0.5569 \cdot x_{5}+0.6110 \cdot x_{6}+ \\
0.1731 \cdot x_{7}+0.0673 \cdot x_{8}-0.0042 \cdot x_{9}\end{array}$ & 6.7134 \\
\hline & TFR & $\begin{array}{l}y=(2.4004,0.0072)+(0.0023,0.0031) \cdot x_{1}+(0.0452,0.0024) \cdot x_{2}+(0.0150,0.0097) \cdot x_{3}+ \\
(-0.0343,0.0014) \cdot x_{4}+(-0.0921,0.0028) \cdot x_{5}+(0.2860,0.0057) \cdot x_{6}+(0.0833,0.0050) \cdot x_{7}+ \\
(-0.0514,0.0814) \cdot x_{8}+(-0.0228,0.0143) \cdot x_{9}\end{array}$ & 6.3738 \\
\hline & PFR & $\begin{array}{l}y=(2.4584,0)+(-0.0336,0.5852) \cdot x_{1}+(0.1332,0) \cdot x_{2}+(0.0121,0) \cdot x_{3}+(-0.1086,0) \cdot x_{4}+ \\
(-0.4029,0) \cdot x_{5}+(0.6217,0) \cdot x_{6}+(0.2961,0.095) \cdot x_{7}+(-0.1230,1.3129) \cdot x_{8}+(- \\
0.1026,0.4762) \cdot x_{9}\end{array}$ & 7.6739 \\
\hline & IFR & $y=(1.1201,0) \cdot x_{6}^{2} \cdot x_{5}+(-0.0206,0.3143) \cdot x_{6}+(1.0444,0) \cdot x_{2}+(0.0366,0)$ & 0.0582 \\
\hline \multirow[t]{4}{*}{$\mathrm{H}-\mathrm{B}$} & SR & $\begin{array}{l}y=2.2905-0.1365 \cdot x_{1}-0.0710 \cdot x_{2}+0.0776 \cdot x_{3}-0.2116 \cdot x_{4}-0.3376 \cdot x_{5}+0.2183 \cdot x_{6}+ \\
0.9195 \cdot x_{7}+0.2235 \cdot x_{8}-0.0471 \cdot x_{9}\end{array}$ & 9.8682 \\
\hline & TFR & $\begin{array}{l}y=(1.7676,1.4951)+(0.0167,0) \cdot x_{1}+(-0.0845,0) \cdot x_{2}+(0.1098,0) \cdot x_{3}+(- \\
0.2344,0.9374) \cdot x_{4}+(0.0383,0) \cdot x_{5}+(0.2897,0) \cdot x_{6}+(0.8183,0) \cdot x_{7}+(0.1816,1.3757) \cdot x_{8} \\
+(0.0702,0) \cdot x_{9}\end{array}$ & 8.8092 \\
\hline & PFR & $\begin{array}{l}y=(2.3254,0.0412)+(-0.0364,0) \cdot x_{1}+(-0.0064,0) \cdot x_{2}+(0.0290,0) \cdot x_{3}+(- \\
0.0923,0.0260) \cdot x_{4}+(-0.0609,0) \cdot x_{5}+(0.0299,0) \cdot x_{6}+(0.4065,0) \cdot x_{7}+(-0.0900,0.0901) \cdot x_{8} \\
+(0.0007,0) \cdot x_{9}\end{array}$ & 8.2113 \\
\hline & IFR & $y=(3.6920,0) \cdot x_{4}+(-0.1531,0) \cdot x_{8}+(0.0165,0.2423) \cdot x_{8}^{2}+(-0.5189,0) \cdot\left(x_{8}+x_{7}^{2}+x_{4} \cdot x_{7}\right)$ & 0.0756 \\
\hline
\end{tabular}


Table 5 Means and variances of the prediction errors of the affective responses

\begin{tabular}{|l|l|c|c|c|c|}
\hline & & $\begin{array}{c}\text { Statistical } \\
\text { regression }\end{array}$ & $\begin{array}{c}\text { Takagi's } \\
\text { fuzzy } \\
\text { regression }\end{array}$ & $\begin{array}{r}\text { Peters' } \\
\text { fuzzy } \\
\text { regression }\end{array}$ & $\begin{array}{c}\text { Intelligent } \\
\text { fuzzy } \\
\text { regression }\end{array}$ \\
\hline \multirow{2}{*}{ S-C } & Mean (\%) & 12.825 & 17.794 & 12.473 & 6.7548 \\
\cline { 2 - 6 } & Variance (\%) & 106.31 & 136.68 & 76.801 & 34.693 \\
\hline \multirow{2}{*}{ U-G } & Mean (\%) & 9.279 & 11.319 & 10.953 & 5.8147 \\
\cline { 2 - 6 } & Variance (\%) & 31.849 & 50.093 & 45.178 & 9.1224 \\
\hline \multirow{2}{*}{ H-C } & Mean (\%) & 8.9346 & 9.1336 & 8.5013 & 4.9788 \\
\cline { 2 - 6 } & Variance (\%) & 32.941 & 36.819 & 33.346 & 11.505 \\
\hline \multirow{2}{*}{ H-B } & Mean (\%) & 11.216 & 13.923 & 12.473 & 8.3124 \\
\cline { 2 - 6 } & Variance (\%) & 48.739 & 73.713 & 76.801 & 52.673 \\
\hline
\end{tabular}

